\title{
A Reforma da Educação Superior Portuguesa
}

José Ferreira Gomes ${ }^{1}$

\begin{abstract}
Resumo: A universidade europeia atravessa um período de grandes reformas com o duplo objectivo de melhorar a eficiência face à escassez de recursos públicos e de melhorar a eficácia da resposta às necessidades da moderna sociedade do conhecimento. Apesar do esforço de articulação representado pelo processo de Bolonha, a cadência das reformas obedece à agenda política nacional de cada país e estas nem sempre parecem convergentes. Em Portugal, estão em curso uma série de reformas que prometem alterar a face da educação superior. A massificação da educação superior deu-se com um atraso considerável em relação à maioria dos países do continente europeu obrigando as instituições a transformações muito rápidas nos últimos anos. O crescimento muito acelerado da procura levou à criação de um sector privado que chegou a receber metade dos estudantes mas que entrou depois em regressão sem chegar a atingir padrões de qualidade reconhecidos. Este artigo tem por objetivo analisar a reforma da educação superior portuguesa.
\end{abstract}

Palavras-chave: Educação superior; reforma; Portugal.

\section{The Reform of the Portuguese Higher Education System}

\begin{abstract}
The European university faces a period of major reforms with a twofold purpose of improving not only the efficiency in the face of scarce public financial resources, but also the efficacy of the response to the knowledge society needs. Despite the effort of articulation represented by the Bologna process, the rhythm of reforms is directed related to national policy agenda of each country and these agendas do not always seem to converge. There are many reforms in course in Portugal that promise to change the face of its higher education. The massive access to higher education took place with a considerable delay in relation to most European countries requiring institutions to change very fast in recent years. The accelerated growth in demand led to the creation of a private sector that absorbed half of the students. However, this sector was reduced later on without achieving
\end{abstract}


GOMES, J. F. A Reforma da Educação Superior ...

recognized standards of quality. This paper aims at analysing the reform of the Portuguese higher education.

Keywords: Higher education; reform; Portugal.

JEL: R 10

\section{Introdução}

A Universidade foi criada em Portugal no século XIII acompanhando o movimento geral do ocidente europeu (vide Figura 1). Inicialmente localizada em Lisboa, veio a fixar-se definitivamente em Coimbra no início do século XVI.

FIGURA 1 - MAPA DA EUROPA COM AS UNIVERSIDADES CRIADAS NOS SÉCULOS XIII E XIV

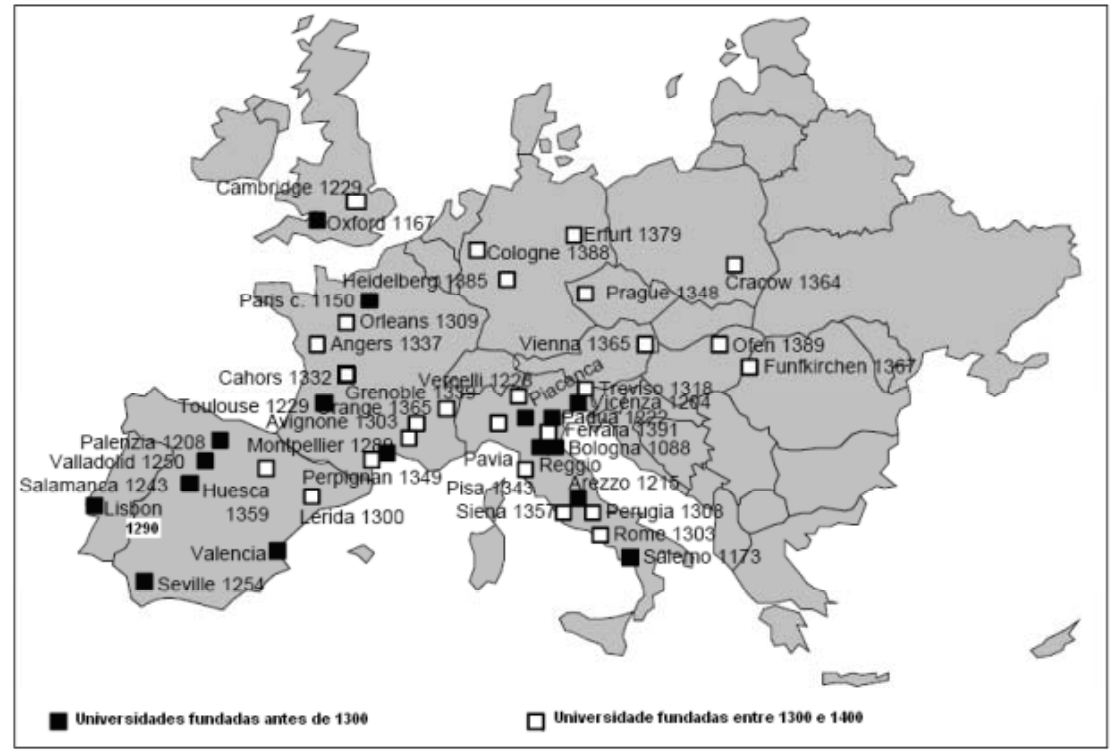

Em 1559, foi criada a Universidade Jesuíta de Évora que não sobreviveu à expulsão da ordem em 1759. Com a reforma da Universidade em 1772, o Marquês de Pombal introduziu os estudos das ciências experimentais mas este esforço de renovação veio a ter um fim abrupto com as invasões napoleónicas de 1807-12 a que se seguiu a guerra civil. Depois da extinção 
das ordens religiosas em 1834, começa o estabelecimento de um sistema de instrução pública e a criação de Escolas Politécnicas em Lisboa e Porto que recebem o estatuto de universidade em 1911, logo após a revolução republicana.

A crise financeira decorrente da primeira Guerra e da depressão dos anos trinta impediu o desenvolvimento rápido das três universidades de Coimbra, Lisboa e Porto, o que veio a ser continuado por políticas diacrónicas do Estado Novo até à sua extinção em 1974. De facto, Portugal por razões de ideologia política e a Espanha pelo isolamento a que foi forçada depois da Guerra Civil de 1936-38, não acompanharam inicialmente a expansão económica e da educação superior no pós-guerra.

Usando dados do Eurostat Yearbook 2003 e de 2006-07, o Quadro 1 apresenta uma estimativa do número de estudantes universitários por milhar de habitantes de 1950 até 2004, mostrando como Portugal fez a massificação tardia. Hoje as populações europeias estão a envelhecer e mantêm-se estacionárias, com a consequência de que o número de estudantes começou a estabilizar na maioria dos países.

QUADRO 1 - NÚMERO DE ESTUDANTES NO ENSINO SUPERIOR POR 1000 HABITANTES

\begin{tabular}{|c|c|cc|c|c}
\hline Portugal & Espanha & França & Italia & Grécia & Bélgica \\
\hline 37,6 & 43.5 & 35.9 & 34.3 & 54.3 & 37,1 \\
\hline Irlanda & Alemanha & R. Unido & EU-25 & EEUU & Japão \\
\hline 47 & 28,3 & 37,6 & 37,9 & 57.7 & 31,6 \\
\hline
\end{tabular}

Fonte: Eurostat Yearbook (2006-7)

O número de estudantes no ensino superior tem hoje grandes variações, entre pouco mais de $30 \%$ como no Japão até perto de $60 \%$ como nos Estados Unidos. Deve notar-se que estes números têm pouco relação com a taxa de acesso porque o tempo médio de permanência dos estudantes é muito variável conforme a estrutura de cursos ou os hábitos de cada país. Por outro lado, a noção de educação superior é também variável com alguma educação típica dos Community Colleges americanos a ser classificada como educação não superior noutros países.

Deve notar-se que a população no ensino superior está praticamente estabilizada na EU-15, com um crescimento de apenas 10\% no quinquénio 1999-2004, estando mesmo em contracção em Portugal e em Espanha (Figura 2). 
FIGURA 2 - A POPULAÇ̃̃O ESTUDANTIL (EDUCAÇÃO SUPERIOR) EM ALGUNS PAÍSES EUROPEUS, POR MILHAR DE HABITANTES

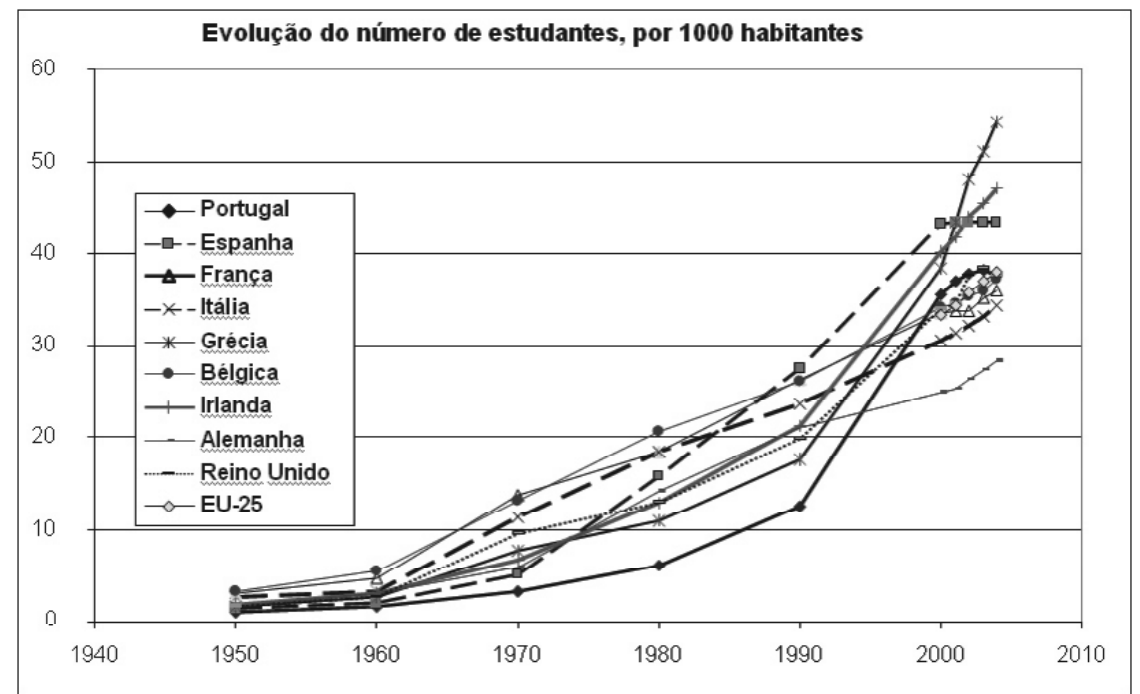

Fonte: Eurostat Yearbook (2006-7)

Nota: Para a União Europeia a 25 países apresentam-se dados para os anos 2000-2004.

\section{A demografia da Educação Superior}

Portugal tem um sistema binário com 14 universidades públicas e 15 institutos politécnicos públicos. O sector privado tem 15 universidades e mais de 100 instituições especializadas de pequena dimensão. Como vimos atrás, houve uma expansão rápida e relativamente tardia. Entre 1985 e 1995, as instituições públicas não foram capazes de dar resposta à explosão da procura o que permitiu o estabelecimento de instituições privadas. O enfraquecimento da procura veio a atingir primeiro estas e depois os institutos politécnicos públicos, sendo o efeito sobre as universidades públicas mais moderado (Figura 3). Note-se que a percentagem de mulheres entre os diplomados pela educação superior portuguesa atingiu já os $67 \%$, o que pode ser comparado com $57 \%$ em Espanha. 
FIGURA 3 - EVOLUÇÃO DA POPULAÇÃO ESTUDANTIL PORTUGUESA, POR TIPO DE INSTITUIÇẪO DE EDUCAÇÃO SUPERIOR

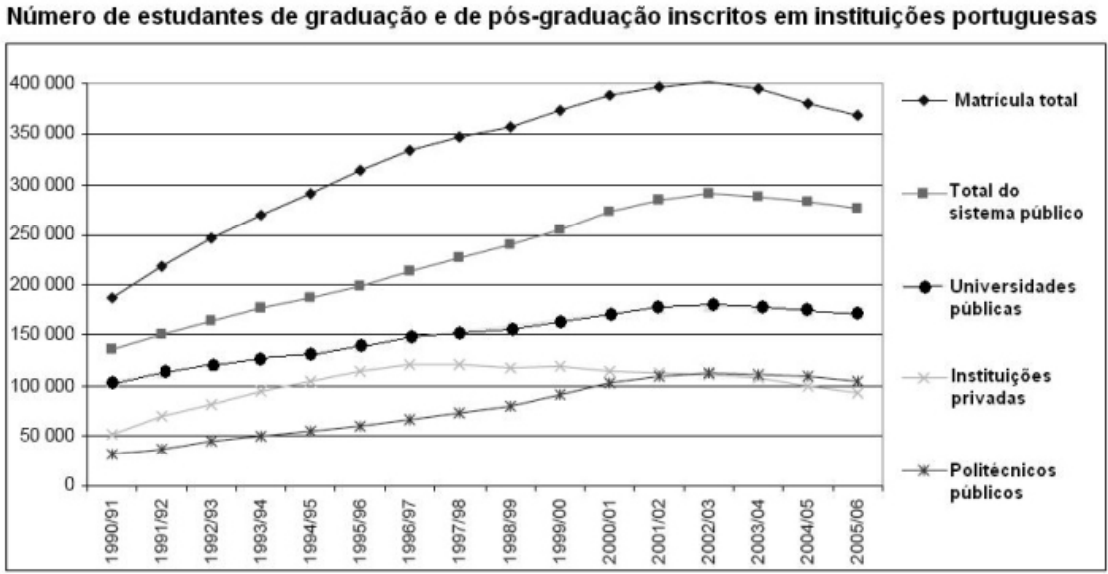

Fonte: Eurostat Yearbook (2006-7).

As universidades públicas portuguesas gozam de um elevado grau de autonomia quando comparadas com as congéneres do continente europeu, podendo criar livremente cursos em qualquer área do conhecimento. $\mathrm{O}$ controlo governamental faz-se sentir através da fixação do número de vagas de entrada em cada curso de licenciatura. O racional desta política é ostensivamente de regulação da rede pública, embora os aspectos orçamentais não estejam muito arredados do decisor político.

O desemprego de licenciados começa a ser uma preocupação em anos recentes. Apesar de o desemprego estatístico ser sistematicamente mais baixo entre os licenciados do que na população em geral, é claro que as políticas de restrição orçamental levaram a uma afrouxamento na contratação de licenciados pelo Estado. Ora sendo este ainda o grande empregador de licenciados, não pode deixar de haver efeitos imediatos. Acresce que houve nos últimos anos uma contracção do número de estudantes em todos os níveis educativos, o que criou grandes dificuldades nos cursos de formação de professores. É previsível que se venha a dar o ajuste social ao súbito crescimento da educação superior na década de 1990. Este mesmo efeito foi observado noutros países europeus e até na China o ministro do trabalho e da segurança social exprimiu recentemente a dificuldade de a economia acompanhar o elevado ritmo de crescimento da educação superior nos últimos anos (China Daily (Xinhua), 8 de Maio de 2006): Com um aumento anual de $20 \%$, o número de licenciados lançados no mercado de trabalho atingiu 4,13 milhões o que ultrapassou temporariamente a procura por uma economia, mesmo em rápido crescimento.

Ao nível de pós-graduação, em Portugal também o número de doutores 
vem crescendo a perto de $10 \%$ ao ano. Este índice tem reflexo na produção científica que, cresce a um ritmo ainda superior mas começa a haver grande dificuldade de inserção profissional por se ter encerrado o ciclo de rápida expansão da educação superior. Começa a ver-se um notável dinamismo de alguns destes jovens doutores para construírem o seu próprio emprego pela criação de pequenas empresas de base tecnológica para o que foram criados importantes apoios públicos e parceiras público-privadas, mas é demasiado cedo para decidir do sucesso desta política.

\section{O financiamento da Educação Superior}

O financiamento do sistema público é feito por uma fórmula acordada no início dos anos de 1990. Nesta fórmula são considerados vários aspectos da realidade de cada universidade mas a dependência mais visível é do número total de estudantes inscritos em cada licenciatura e no primeiro ano de mestrado. Está também fixada uma razão docente/discente para cada área disciplinar, o que permite às universidades gerir autonomamente os seus quadros docentes e de funcionários não docentes. Toda esta maquinaria funcionou muito bem na fase de expansão, estimulando as universidades a aumentar e diversificar a sua oferta educativa. Contudo os problemas começaram logo a ser visíveis na dificuldade orçamental de sucessivos governos cumprirem a fórmula acordada. Posteriormente, tornou-se evidente que universidades do interior e das ilhas (Madeira e Açores), mais pequenas e com menor procura pelos estudantes, não poderiam sobreviver ao financiamento por fórmula o que forçou o ministro responsável a inventar anualmente novos critérios de solidariedade ou de convergência que evitasse roturas financeiras nas mais frágeis à custa de efectivas transferências do orçamento nominal das maiores universidades. Nos últimos anos a despesa pública global com a educação superior manteve-se estacionária mas em 2007 sofreu um corte efectivo de perto de $15 \%$. A posição comparativa é apresentada na Figura 4, onde são usados valores relativos a 2004 e são mostradas as despesas (pública a azul e privada a cinza) em percentagem do produto nacional. 
FIGURA 4 - DESPESA NACIONAL (EM PERCENTAGEM DO PIB) COM A EDUCAÇÃO SUPERIOR

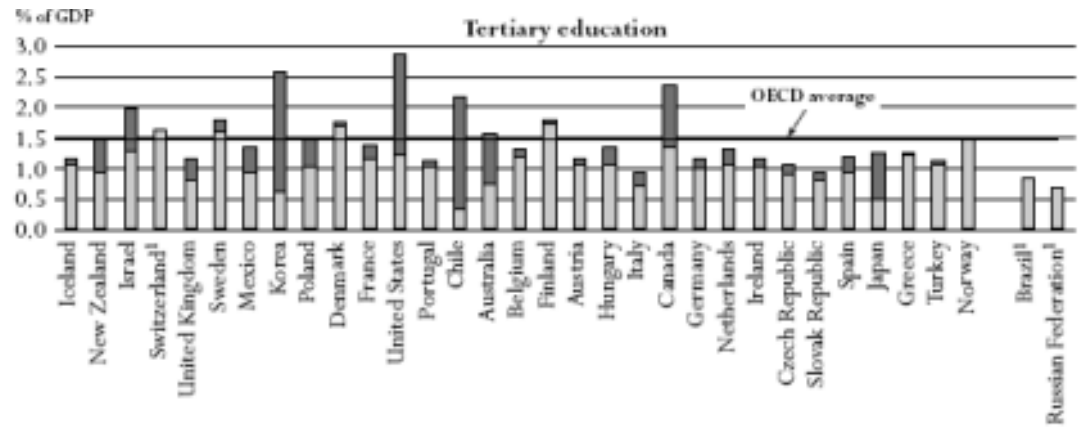

Fonte: OECD, Eduaction at a Glance, 2006.

A quebra do financiamento público acentuou-se nos anos mais recentes. O efeito prático é que as instituições estão a operar abaixo do ratio docente/ discente que fora definido. A Figura 5 mostra que a quebra orçamental foi mais forte do que a quebra do número de estudantes que se verifica desde 2003 quer nas universidades quer nos institutos politécnicos. As taxas estudantis foram fixadas em €6 por ano em 1941 e este valor manteve-se até aos anos de 1990. Só então foi feita a correcção monetária apesar dos grandes protestos estudantis. Em 2003 foi estabelecido que cada instituição poderia fixar o seu valor entre €450 e €850 com estes limites indexados à inflação. Note-se que esta subida foi insuficiente para compensar o abaixamento do financiamento público. 
FIGURA 5 - CUSTO POR ESTUDANTE DO SISTEMA PÚBLICO DE EDUCAÇÃO SUPERIOR

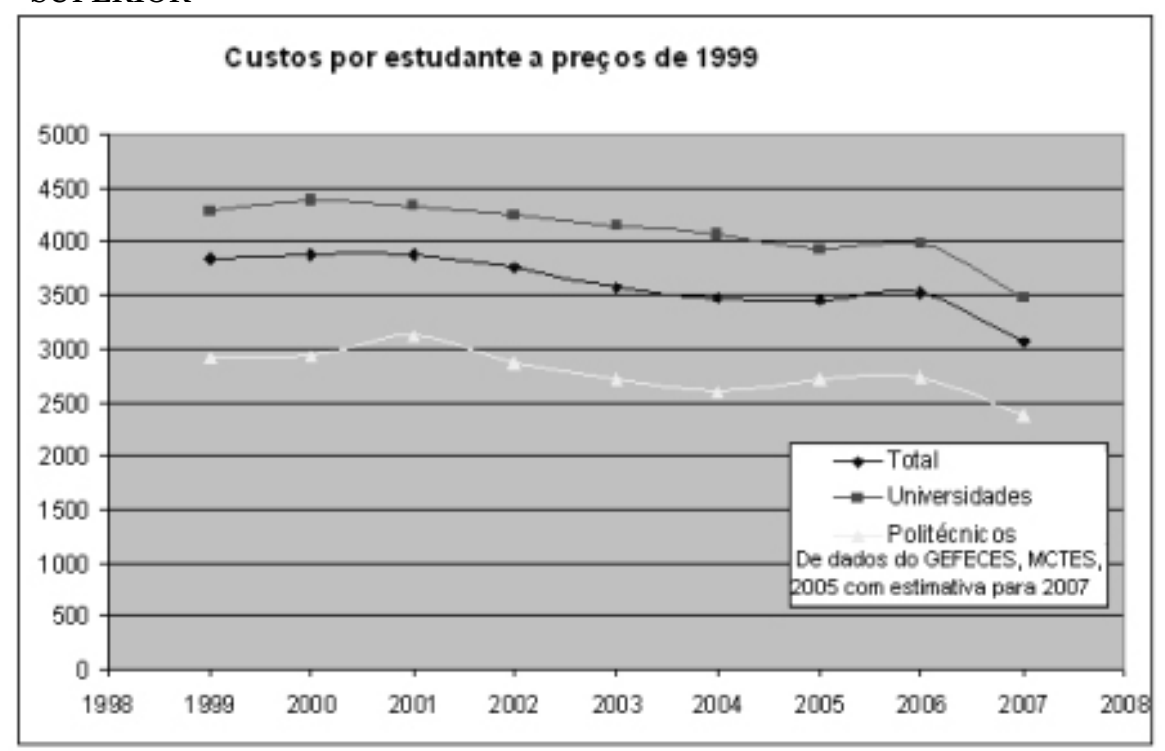

Fonte: OECD, 2006.

É demasiado cedo para apreciar os efeitos do corte orçamental de 2007 mas têm sido noticiados despedimentos de docentes em muitas universidades e institutos politécnicos públicos. Do lado das instituições privadas, são conhecidas dificuldades financeiras que, em alguns casos, são difíceis de distinguir de simples casos de polícia que também se têm repetido.

\section{A estrutura de graus acadêmicos}

Tradicionalmente, o curso de graduação base para entrada no mercado de trabalho era a licenciatura com uma duração nominal variável de 4 a 6 anos, 4 anos para as áreas de Ciências e Humanidades, 5 anos para as Engenharias e a formação de professores e 6 anos para Medicina, Medicina Dentária, Farmácia e Arquitectura. A pós-graduação tinha as alternativas de Mestrado com a duração de 1 a 2 anos e o doutoramento com a duração mínima de 3 anos. A inscrição no Mestrado exigia a licenciatura prévia. A inscrição no doutoramento era normalmente antecedida pelo Mestrado, embora um licenciado com boa classificação final pudesse passar directamente da licenciatura para o doutoramento. Aquando da criação dos institutos politécnicos na década de 1980, estes foram autorizados a oferecer um curso mais curto, um Bacharelato de 3 a 4 anos. Mais tarde vieram a ser autorizados a oferecer um segundo ciclo de 2 anos com equivalência formal a uma licenciatura Os 
institutos politécnicos não estavam autorizados a oferecer mestrados nem doutoramentos.

A adequação a Bolonha foi regulamentada em 2005 e levou à introdução de uma licenciatura de 3 anos seguida de um mestrado com a duração típica de 2 anos (Figura 6). Os cursos profissionais (engenharias, medicina, arquitectura, etc.) foram autorizados a manter um modelo próximo do anterior, o chamado mestrado integrado com a duração de 5 ou 6 anos. Os institutos politécnicos estão autorizados a oferecer a licenciatura e o mestrado mas este só está a ser autorizado muito selectivamente nos casos em que é demonstrado bom desempenho de investigação na área respectiva. O doutoramento com a duração mínima de três anos mantém-se reservado às universidades. Foi introduzida a novidade dos Cursos de Especialização Tecnológica (CET) com a categoria de educação pós-secundária que poderão ser oferecidos em institutos politécnicos ou em escolas secundárias sob a supervisão de uma universidade ou instituto politécnico. A transferência para o novo modelo foi muito rápida mas é ainda cedo para apreciar o impacto dos novos graus académicos no mercado de trabalho. Não é claro que as novas licenciaturas universitárias de três anos estejam a ser desenhadas com uma preocupação de empregabilidade dos futuros licenciados e é previsível que a sociedade tenha alguma dificuldade em compreender o novo nível de competências que se pretende introduzir.

FIGURA 6 - ESQUEMA DA ORGANIZAÇÃO DA EDUCAÇÃO SUPERIOR PORTUGUESA ANTES E DEPOIS DA ADEQUAÇÃO A BOLONHA FEITA PELA LEGISLAÇÃO DE 2006
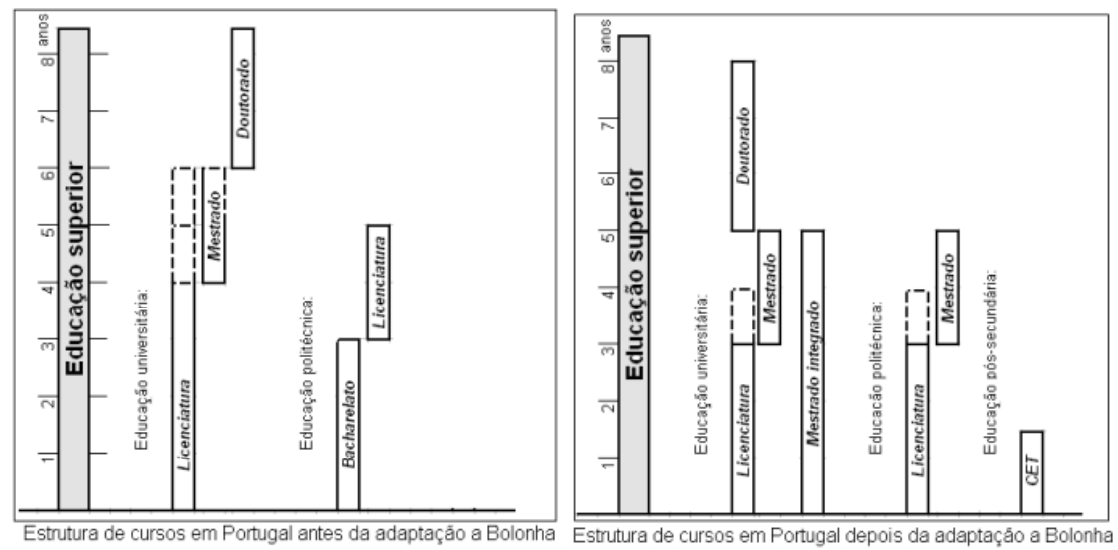

Source: OECD, 2007. 
Um problema generalizado era o baixo prestígio social dos antigos bacharéis, mesmo em áreas com uma elevadíssima aceitação pelo mercado de trabalho. Esta realidade levava a maioria dos Bacharéis a procurarem prosseguir estudos de segundo ciclo mas, em geral, como estudantes trabalhadores. Esta foi uma das razões invocadas para dar a designação de licenciatura ao novo primeiro ciclo de três anos. As dificuldades criadas pelo Governo para autorizar o funcionamento dos mestrados nos institutos politécnicos parece sinalizar uma intenção de dificultar a continuação de estudos quase automática. A manter-se a posição actual, muitos estudantes terão de procurar o segundo ciclo numa universidade ou num instituto politécnico diferente daquele onde terminaram a licenciatura. A resposta a estas dúvidas só poderá ser dada depois de o novo sistema estabilizar dentro de alguns anos.

\section{Apoio social aos estudantes}

O sistema de apoio social aos estudantes tem duas componentes administradas por uma entidade anexa a cada instituição pública e por um serviço central responsável pelos institutos privados. Nas instituições públicas os serviços sociais dependem do Reitor/Presidente mas seguem normas gerais nacionais. Cada instituição mantém uma rede de cantinas e de residências subsidiadas. Adicionalmente, são concedidas bolsas de estudo aos estudantes cujo rendimento familiar não atinja um limiar definido. No sector público, $17 \%$ dos estudantes beneficiam de bolsa contra $13 \%$ no privado. Em 2004, o valor médio de cada bolsa foi de $€ 1500$ nos estudantes universitários, $€ 1200$ nos do politécnico e de $€ 1700$ nos do sector privado. Estas diferenças traduzem essencialmente o diferencial de propinas por as universidades terem assumido quase sempre o valor máximo permitido enquanto que os politécnicos se mantiveram com valores mais baixos; no sector privado, a bolsa inclui uma componente para pagamento das taxas de frequência mas este valor é limitado para não estimular a sua subida pelas instituições. Aquando do aumento da taxa de frequência, o governo prometeu compensar os estudantes carenciados e por esta razão há muitas bolsas equivalentes ao valor da taxa. 


\section{FIGURA 7 - DESPESA PÚBLICA COM O APOIO AOS ESTUDANTES}

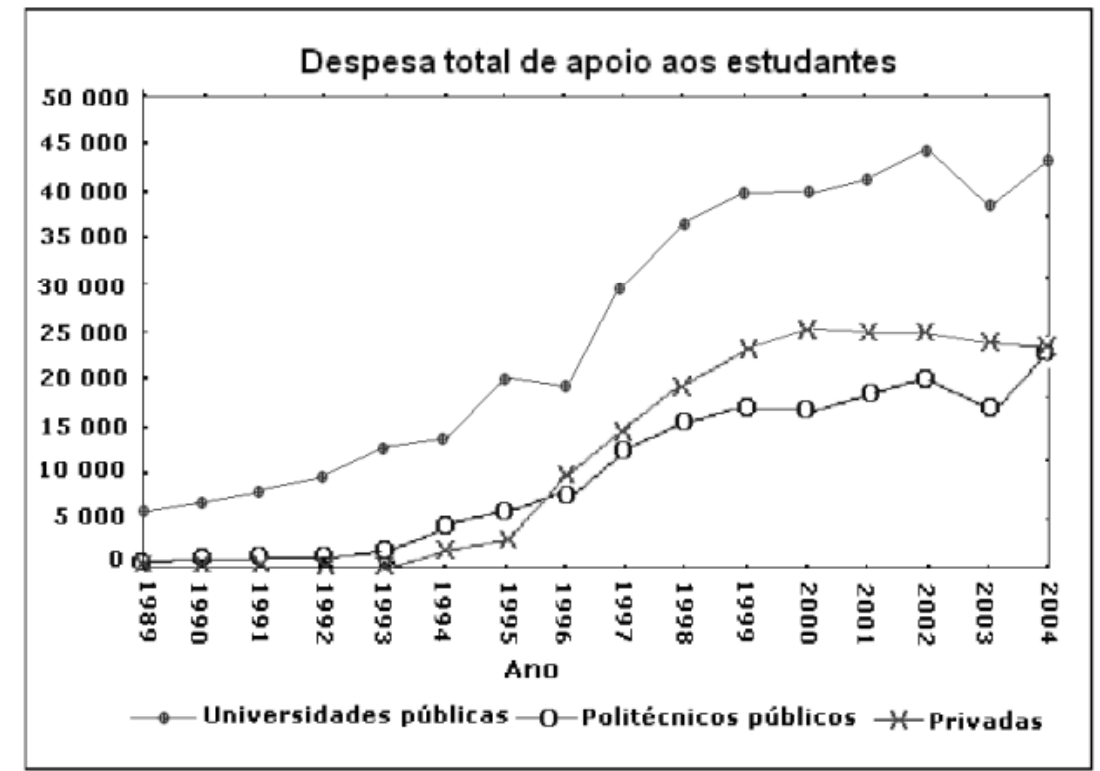

Fonte: adaptado de OECD, Reviews of National Policies for Education - Tertiary Education in Portugal (2007).

A figura 7 mostra a despesa total de apoio social aos estudantes da educação superior. A quebra da despesa com estudantes das privadas reflecte a baixa de frequência enquanto que o sector público se mantém estacionário. Cerca de $60 \%$ desta despesa refere-se à atribuição de bolsas.

\section{Acesso}

A grande barreira social ao acesso à educação superior situa-se aos 15 anos, na transição da educação básica obrigatória para a educação secundária. Dentro da educação superior o sistema de apoio social resolve as situações limite sem compensar outras distorções de factores socio-económicos. Um estudo apresentado por Amaral et al na $28^{\mathrm{a}}$ reunião anual da EAIR (Roma, Setembro de 2006) mostrou um claro inviezamento das escolhas dos estudantes. Estudantes de níveis socio-económicos mais carenciados ou em primeira geração na educação superior tendem a preferir os institutos politécnicos e a estar menos representados nos cursos mais competitivos de saúde e de ciência e tecnologia. De facto, o sistema nacional de acesso às instituições públicas dá um peso muito grande à classificação terminal do secundário que pode ser 
melhor conseguida com recurso a apoio individual ao estudante ou com a sua transferência para uma escola privada. Outro inviezamento que tem sido focado é a maior representação em instituições privadas de estudantes não convencionais, o que pode resultar da sua menor aceitação nas instituições públicas e da menor representação do formato pós-laboral nestas.

\section{Asseguramento da qualidade e acreditação}

A avaliação dos cursos de licenciatura foi introduzida em Portugal em 1993 por iniciativa do Conselho de Reitores das Universidades (Públicas) Portuguesas, CRUP. Nas suas linhas gerais, seguiu-se o modelo Holandês inicial com as duas fases de elaboração de um relatório de autoavaliação seguida da visita da comissão externa que elabora o seu relatório de avaliação. Depois de implementado nas universidades membros do CRUP, este modelo foi assumido na legislação nacional e passou a ser aplicado nos outros subsectores, institutos politécnicos públicos, universidades privadas e institutos politécnicos privados.

Foi já neste quadro legal que funcionou em 2000-2005 o segundo ciclo de avaliação das universidades públicas (e primeiro nos outros sub-sectores). O objectivo deste sistema de avaliação é o de contribuir para a melhoria dos cursos sem efeitos directos no financiamento. A qualidade dos relatórios finais foi algo heterogénea com casos onde a diversidade institucional era bem transparente mas outros onde não era fácil tirar quaisquer conclusões sobre as diferenças de qualidade. A sociedade esperava mais e os governos sucessivos foram pedindo aos avaliadores mais do que o modelo permitia. Uma das dificuldades de base é que as quatro agências responsáveis pelo processo eram de facto entidades representativas das instituições. A outra dificuldade estava no conflito nunca resolvido entre uma avaliação para a melhoria e uma avaliação para a prestação de contas. O processo foi interrompido em finais de 2005 com o anúncio de que seriam criados novos instrumentos legais. O governo pediu à ENQA (rede europeia de agências de qualidade) uma avaliação que terminou em finais de 2006 e foi apresentado em Março de 2007 o projecto de lei que deverá seguir a tramitação legislativa.

É prevista a criação de uma Agência de Avaliação e de Acreditação independente mas com um Conselho Geral nomeado pelo ministro da tutela. Caberá a esta futura agência organizar os processos de avaliação e só poderão funcionar cursos de primeiro, segundo e de terceiro ciclo que estejam acreditados. Com este modelo deverá ser extinto o processo de acreditação pelas ordens profissionais que foi sendo estabelecido nos últimos anos e que decorria independentemente. Particularmente no caso das engenharias (e, em menor grau na arquitectura) este processo de acreditação desenvolvera-se até ao ponto de ser procurado por todas as instituições e se permitir excluir um 
número apreciável de cursos. Em princípio, esta não acreditação excluía do exercício profissional estudantes que tinham concluído um curso aprovado pelo governo. Na prática, funcionava como uma etiqueta de qualidade com certo reconhecimento social.

Na nova proposta do governo, pretende-se que a avaliação pela Agência a criar se expresse "através de uma classificação atribuída, quer a cada um dos parâmetros considerados na avaliação, quer em relação à avaliação global, numa escala que permita ordenar e comparar o objecto de avaliação". Estabelece-se ainda que "a acreditação dos estabelecimentos de ensino superior, seus ciclos de estudos, graus e diploma, no quadro do sistema de garantia de qualidade do ensino superior é realizada com base na avaliação de qualidade".

\section{Rede de instituições de Educação Superior e seu governo}

A educação superior está organizada num sistema binário de universidades e institutos politécnicos. Embora mais de metade dos novos estudantes tenha chegado a entrar em instituições privadas no princípio dos anos de 1990, as instituições públicas retomaram hoje a posição dominante. É geralmente reconhecido que tem havido uma deriva académica dos institutos politécnicos e, possivelmente, uma deriva profissionalizante das universidades. O governo actual reafirmou a firme vontade de manter o sistema binário, procurando clarificar as missões diferenciadas dos dois subsistemas. Os textos legais reservam o terceiro ciclo para as universidades e impõem algumas condicionantes para a autorização de segundos ciclos. A intenção parece ser a de orientar os institutos politécnicos para os primeiros ciclos e os CET, embora o sucesso desta diferenciação não esteja ainda assegurado. Esta dificuldade é comum noutros países europeus onde o nível de acesso é igual. A Alemanha e a Holanda têm sistemas binários bem estabilizados mas o encaminhamento dos estudantes é bem definido ao longo da educação secundária.

Os docentes e os funcionários não docentes das instituições públicas têm o estatuto de funcionário público. O recente relatório da OCDE veio recomendar a possibilidade de as instituições passarem a ter o estatuto de fundações e de ser perdido o estatuto de funcionário público, o que vem apenas reforçar a tendência já defendida em certos sectores do governo. A proposta de Regime Jurídico da Instituições de Ensino Superior que o Governo apresentou em Maio de 2007 propõe um órgão máximo com funções de orientação estratégica, de eleição do reitor/presidente de instituto politécnico e de fiscalização deste com uma composição reduzida a não mais de 25 elementos, dos quais $50 \%$ serão professores e $30 \%$ estudantes, podendo os outros ser cooptados do exterior. Em relação ao modelo anterior, tem a enorme vantagem de reduzir a dimensão, melhorando a sua eficácia potencial; o aumento do peso dado à representação dos professores corresponde entregar formalmente o poder ao 
corpo que já o detinha na prática mas agora de forma mais responsabilizante. A grande inovação é a possibilidade de as instituições adquirirem o estatuto de fundações de direito privado com um conselho de curadores de três a cinco elementos nomeados pelo governo. É este conselho de curadores que tem a responsabilidade de nomear o reitor/presidente do instituto, de aprovar a orientação estratégica e acompanhar a gestão.

O regime de direito privado é bastante atractivo mas o sacrifício da tradicional autonomia de escolha do reitor/presidente sem intromissão política poderá ser visto como demasiado arriscado. O governo inclina-se assim para a via austríaca de nomeação dos curadores quando a prática dinamarquesa já mostrou que a escolha inicial dos curadores pelas próprias universidades pode dar excelentes resultados.

\section{Política científica}

Só desde 2003 é que a política científica depende do mesmo ministério que a educação superior. A grande maioria da investigação científica é realizada em ambiente universitário, liderada por docentes universitários. A rede de Laboratórios do Estado teve pouco investimento nos últimos anos e está agora em plena reorganização sem expansão do número de investigadores. A alternativa de crescimento foi incentivar os investigadores universitários a criarem entidades relativamente autónomas das suas instituições de vinculação e financiadas pelo governo. Tipicamente, a universidade paga os salários de docentes-investigadores seniores destas unidades e permite o seu alojamento. As despesas de funcionamento são suportadas pelo governo através de uma linha de financiamento-base e de projectos competitivos. Um sistema de bolsas de doutoramento e de pós-doutoramento gerido centralmente financia os investigadores juniores que tipicamente estão inscritos numa universidade como estudantes de doutoramento mas desenvolvem a sua actividade enquadrados numa das entidades de investigação e desenvolvimento. Estas unidades são sujeitas a avaliação periódica por um painel de cientistas estrangeiros.

Realizar-se-á em 2007 a quarta avaliação de todas as unidades. O financiamento-base depende do resultado da avaliação, embora a candidatura a projectos esteja aberta a todos os investigadores doutorados de universidades, institutos politécnicos, instituições privadas sem fins lucrativos ou empresas. O importante investimento feito produziu um efeito visível, sendo Portugal o país com maior ritmo de crescimento da produção científica referenciada no Web of Science nos últimos 12 anos, $4 \mathrm{x}$ comparado com 2,1x para a Espanha que é, ela própria, um exemplo de bom desempenho nos últimos decénios (vide Figura 8). Apesar deste crescimento acelerado, a produção científica por milhão de habitantes está ainda abaixo dos concorrentes mais próximos. 
FIGURA 8 - PRODUÇÃO CIENTÍFICA POR MILHÃO DE HABITANTES, EM ALGUNS PAÍSES EUROPEUS

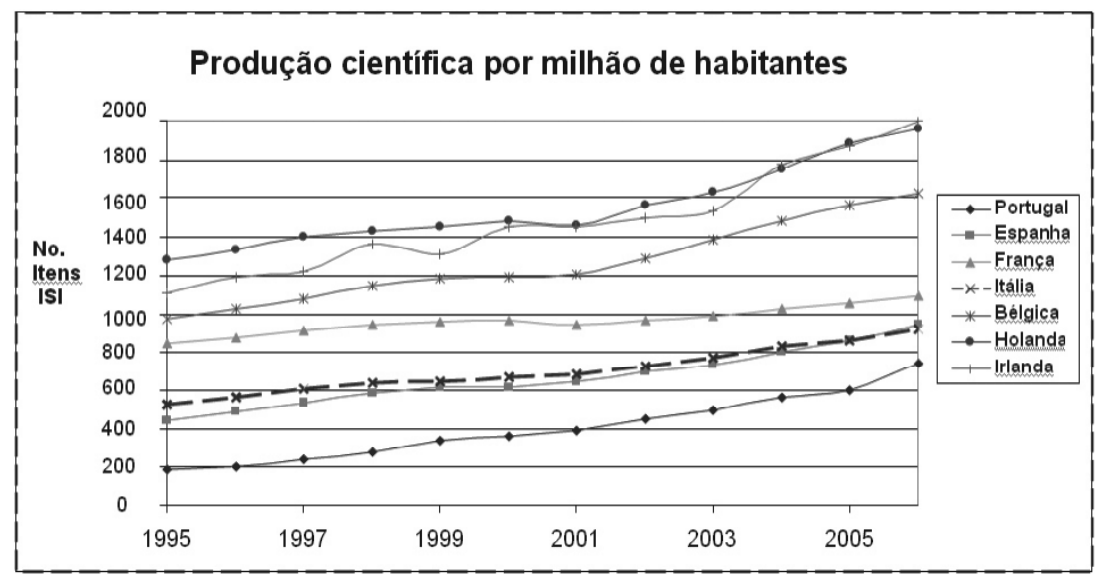

Fonte: Thomson Reuters, Web of Science.

Na transferência do conhecimento proveniente da investigação parece manterse um atraso grande na via da sua valorização através de patentes que pode ser medido pelo baixo número de patentes registadas anualmente. $O$ processo de criação de empresas de base tecnológica é recente e parece estar a ter um impacto importante no meio académico, permitindo acalentar a esperança de que venha a ser relevante na criação de emprego. O governo lançou um programa porventura único de criação de programas conjuntos com grandes universidades americanas (MIT, Carnegie-Mellon, Texas). É demasiado cedo para avaliar o impacto deste programa mas resta a expectativa de que a falta de emprego alternativo nas áreas de tecnologias avançadas possa levar muitos jovens a arriscar e alguns a obter o retorno desejado. 
GOMES, J. F. A Reforma da Educação Superior ...

\section{Bibliografia}

European Union (2007). Eurostat Yearbook 2007, Luxembourg: European Communities.

OECD (2006). Eduaction at a Glance 2006, Paris: OECD.

European Union (2006). Eurostat Yearbook 2006, Luxembourg: European

Communities.

OECD (2007). Reviews of National Policies for Education: Tertiary Education in Portugal, Paris: OECD.

Recebido em: 01 de abril de 2008. Primeira resposta em: 29 de abril de 2008. Aceite em: 20 de fevereiro de 2009. 